\title{
IMPORTANCE OF HISTOPATHOLOGY OF INTUSSUSCEPTION AND EVALUATION OF CAUSE OF INTUSSUSCEPTION IN INFANTS AND CHILDREN- A 4 YEARS STUDY
}

\author{
K. Geetha 1, O. H. Radhika Krishna ${ }^{2}$, Srinivas Reddy P3, Ramesh Reddy Kota4 \\ ${ }^{1}$ Assistant Professor, Department of Pathology, Niloufer Hospitals, Hyderabad, Telangana, India. \\ ${ }^{2}$ Associate Professor, Department of Pathology, Osmania Medical College, Hyderabad, Telangana, India. \\ 3 Professor, Department of Surgery, Niloufer Hospitals, Hyderabad, Telangana, India. \\ ${ }^{4}$ Professor, Department of Paediatric Surgery, Niloufer Hospitals, Hyderabad, Telangana, India.
}

\section{ABSTRACT}

\section{BACKGROUND}

In early childhood, the commonest cause of bowel obstruction is intussusception and is one of the common abdominal emergencies in children. Early diagnosis helps to reduce mortality and morbidity.

The objective of the study is to assess the usefulness/ efficacy of histopathology in intussusceptions. Clinical and radiological features are useful, but histopathology is the final diagnosis which helps in identifying the aetiology of intussusception. Accurate diagnosis is essential as treatment is variable, as histopathological diagnosis of intussusceptions varies from benign to malignant lesions.

\section{MATERIALS AND METHODS}

The study was a retrospective descriptive study of 4 years duration and included 60 cases. The gross specimens and histopathological slides of all the surgically resected specimens of intestines with intussusception at a tertiary paediatric referral centre were studied in detail with clinical and radiological correlation.

\section{RESULTS}

In 4 years study period, from June 2009 to June 2013, 60 cases which were surgically irreducible were resected and sent to histopathology department. The diagnosis was established by barium enema, x-rays or at laparotomy. There were 60 children, age ranging from 15 days to 13 years. Among these children 40 were male and 20 were female, ratio being 2: 1. The age group most commonly affected were less than 1 year. The classic triad of abdominal pain, vomiting and rectal bleeding was encountered in 49 patients. Out of 60 cases, aetiology of intussusception included Meckel's diverticulum $30(50 \%)$, submucosal lymphoid hyperplasia 19 (31.9\%), inflamed appendix 8 (13.3\%), submucosal haematoma $1(1.6 \%)$, polyp $1(1.6 \%)$ and malignant lymphoma 1 (1.6\%). The ileocecal area was the site most commonly involved (82\%). Hypertrophic Peyer's patches of the terminal ileum being responsible for idiopathic intussusception in the ileocolic area. There were 59 benign developmental lesions and 1 malignant tumour. Enlargement of the mesenteric lymph nodes occurred in $35 \%$ cases.

\section{CONCLUSION}

It is important to know the aetiology of intussusception in paediatric age group, because the aetiology varies from benign to malignant lesions.

\section{KEY WORDS}

Intussusceptions, Meckel's Diverticulum, Histopathology, Aetiology, Malignant Tumour.

HOW TO CITE THIS ARTICLE: Geetha K, Krishna OHR, Reddy SP, et al. Importance of histopathology of intussusception and evaluation of cause of intussusception in infants and children- a 4 years study. J. Evolution Med. Dent. Sci. 2018;7(40):4377-4380, DOI: $10.14260 /$ jemds/2018/976

\section{BACKGROUND}

The term "intussusception" defined as a portion of the gut invaginated with another immediately adjacent, almost always it is the proximal; into the distal very rarely indeed is an intussusception retrograde. Intussusception is usually an acute emergency and in advanced cases serious pathophysiological changes occur if not treated timely. The

'Financial or Other Competing Interest': None.

Submission 08-09-2018, Peer Review 21-09-2018,

Acceptance 24-09-2018, Published 01-10-2018.

Corresponding Author:

Dr. O. H. Radhika Krishna

Associate Professor,

Department of Pathology,

Osmania Medical College,

Hyderabad, Telangana, India.

E-mail: othulururadhika@yahoo.co.in

DOI: $10.14260 /$ jemds $/ 2018 / 976$ nature and seriousness of these changes depend on the degree and duration of obstruction and type of intussusception. If intussusception is unrelieved, the blood supply at the obstructive point of intestine is impaired and ultimately necrosis, gangrene, perforation and general peritonitis develop. Intussusception is the condition whereby a segment of proximal intestine is telescoping or invaginates into the lumen of the more distal bowel. The reported incidence of intussusception varies by time and geographic location. The incidence varies from 1 to 4 per 1000 live births. The male: female ratio is 3: 1 . Mostly, in children intussusception occurs in the first year of life and rarely occur before 2 months of age. Intussusception was first described by Barbette of Amsterdam in 1674. After three centuries, its sonographic features were described in $1(1.6 \%)$ in 1977. Since then ultrasonography is the main diagnostic tool of this condition and has got high specificity and sensitivity. The classical triad of symptoms, vomiting, abdominal pain and passage of "red currant jelly" stool. In the classic case severe 
intermittent, colicky pain begins suddenly in an infant followed after a few hours by vomiting and the passage of blood and mucus from the rectum. Barium enema is both diagnostic and therapeutic. The obstructing mass of invaginated bowel can be recognised and if the congestion and oedema are not too advanced. The applicable of hydrostatic pressure by the radiologist reduce the Intussusception. Operative reduction is required if barium enema reduction fails as it happens is $20-30 \%$ of cases. Gangrene of portion of the Intussusception necessitates segmental intestinal resection in approximately $10 \%$ of cases. These specimens exhibit oedema, congestion, coagulative and haemorrhagic necrosis indicative of combined ischaemia and venous outflow obstruction. Approximately $10 \%$ of cases of childhood Intussusception do not confirm the typical picture. In children past infancy and in atypically located Intussusception discrete lead point is usually identified, Meckel's diverticulum. Polyps, small intestinal duplications, Burkitt's lymphoma and even the appendix have been implicated. Meckel's diverticulum is the most common vitelline duct remnant and also the most common congenital anomaly of the gastrointestinal tract. It results from incomplete obliteration of the vitelline duct at the ileum and appears as a finger-like protrusion of intestine measuring 1-5 $\mathrm{cm}$ on the antimesenteric surface of the middle ileum. Meckel's diverticulum invert into the intestinal lumen and serve as the lead point of an ileoileal intussusceptions.

\section{MATERIALS AND METHODS \\ Study Design}

Retrospective descriptive study.

\section{Study Period}

4 years (June 2009 to June 2013).

\section{Source}

All the surgical cases, which were irreducible are resected and segment of intestine sent to Histopathology Department in Paediatric Institute (Niloufer Hospital).

\section{Cases Studied}

- 60 cases.

- All the aetiological, gross and histopathology findings are studied.

\section{RESULTS}

In 4 years study period from June 2009 to June 2013, 60 cases were studied which were surgically irreducible were resected and sent to Histopathology Department after the diagnosis was established by barium enema-rays or at laparotomy.

\section{Demographic Data}

There were a total of 60 children of age ranging from 15 days to 13 years. Among them male were 40 , whereas the female was 20 in 2: 1 ratio and the most commonly affected group were less than 1 year of age. Most common cause of intestinal obstruction was seen between 3 months and 6 years of age.

\section{Histopathological Diagnosis}

The classic triad of abdominal pain, vomiting and rectal bleeding was encountered in 49 patients. Out of 60 cases aetiology of intussusception include Meckel's diverticulum 30 (50\%), submucosal lymphoid hyperplasia 19 (31.9\%), inflamed appendix 8 (13.3\%), submucosal haematoma 1 (1.6\%), polyp $1(1.6 \%)$ and malignant lymphoma $1(1.6 \%)$. The ileocecal area was the site most commonly involved (82\%). Hypertrophic Peyer's patches of the terminal ileum being responsible for idiopathic intussusception in the ileocolic area. There were 59 benign developmental lesions, 1 malignant tumour. Enlargement of the mesenteric lymph nodes occurred in $35 \%$ cases.
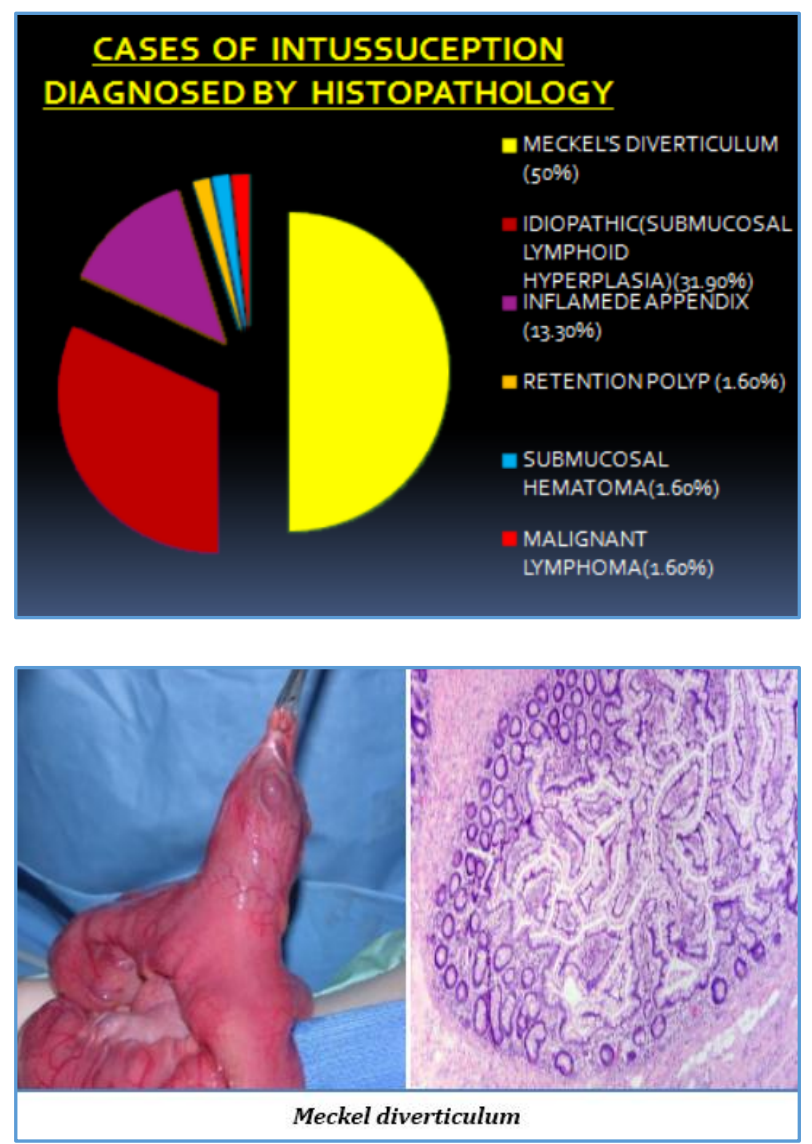

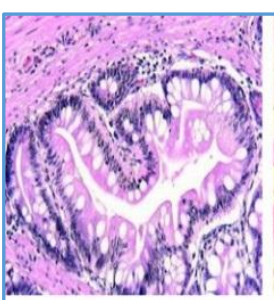

Polyp

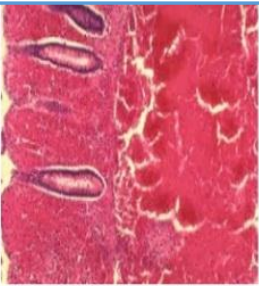

Submucosal hematom
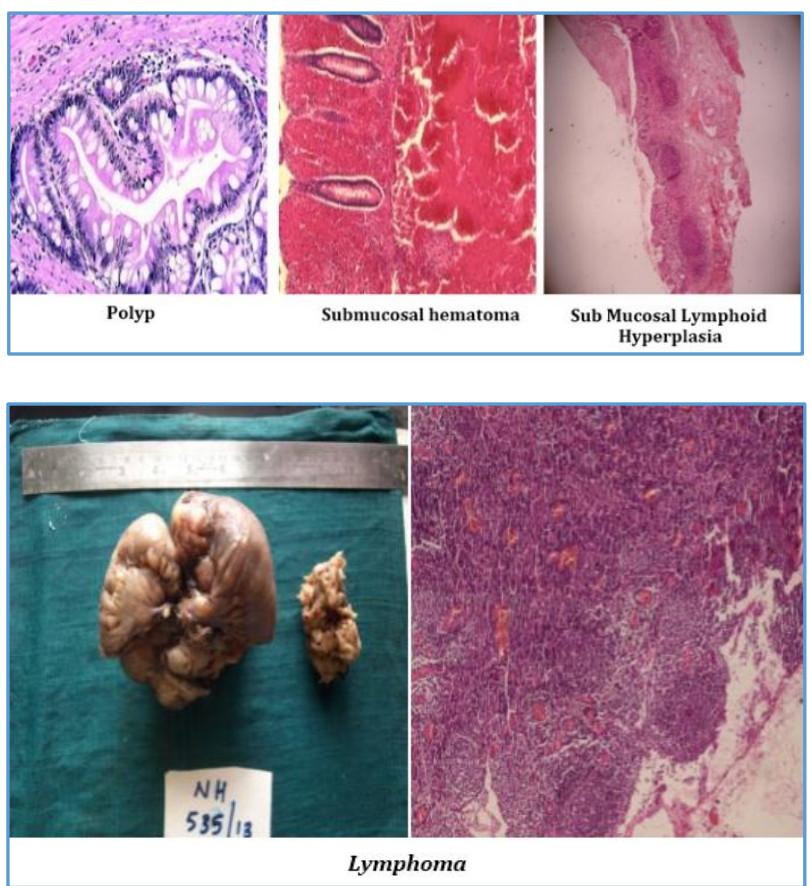


\section{DISCUSSION}

Intussusception is one of the common paediatric surgical emergencies in children with an estimated occurrence of 1-4 per 1000 live births.[1] The present study retrospectively analysed 4 years of Intussusceptions data, which were surgically irreducible were sent to Histopathology Department. Among all the 60 cases in the present study, patients were diagnosed by barium enema, $\mathrm{x}$-rays or laparotomy. The patient's age was ranging from 15 days to 13 years of age and the sex ratio of male was 40 , whereas the female was 20 in 2: 1 ratio and the most commonly affected group was less than 1 year of age.

The preponderance of males observed in this study is concordant with similar findings from studies all over the world. The male-female ratio of 1.8: 1 in Sanjay Mehendale et al.[2] In our study it is 2: 1, lower than reported from the previous Indian studies.

The cases presented with triad of symptoms with rectal bleeding being commonest. The various reasons for intussusceptions were analysed with histopathological findings showed Meckel's diverticulum in 30 cases (50\%), submucosal lymphoid hyperplasia 19 (31.9\%), inflamed appendix 8 (13.3\%), submucosal haematoma 1 (1.6\%), polyp $1(1.6 \%)$ and malignant lymphoma $1(1.6 \%)$. The ileocecal area was the site of most commonly involved (82\%), hypertrophic Peyer's patches of the terminal ileum being responsible for idiopathic intussusceptions in the ileocolic area. There were 59 benign developmental lesions and 1 malignant tumour. Enlargement of the mesenteric lymph node occurred in $35 \%$ cases. It is important to know the aetiology of Intussusceptions in paediatric age group, because diagnosis of intussusceptions varies from benign to malignant lesions. Accurate diagnosis is essential as treatment is variable.

Meckel's diverticulum is known classically to be in $2 \%$ of individuals. Children younger than 2 years old more commonly develop symptoms. It is usually located 2 feet proximal to the ileocecal valve and measures 2 inches on an average. Meckel's diverticulum is known to contain two types of ectopic tissues.[3-5]

Meckel's presents commonly with intussusception. The index of suspicion should be highest in children younger than age 4, who present with intestinal obstruction and no prior history of abdominal surgery.[6,7] Meckel's diverticulum may be clinically silent or become symptomatic at any age. Children younger than 4 years are at greatest risk of having a symptomatic Meckel's diverticulum.

Meckel's diverticulum being the commonest and ileocolic area being the commonest area of intussusceptions. Meckel's diverticulum results from incomplete obliterations of the vitelline duct at the ileum and appears as a finger-like protrusion of intestine measuring $1-5 \mathrm{~cm}$ on the antimesenteric surface of the middle ileum. Meckel's diverticulum invert into the intestinal lumen and serve as the lead point of an ileoileal intussusceptions.

Meckel's diverticulum was the commonest aetiology of intussusception in our study. It is against the study of BM Singhal et al.[8]

Although, lymphoid hyperplasia is a non-specific reactive changes that may occur anywhere in the intestinal tract, it occurs more often within the distal portion of the ileum or rectum. Lymphoid tissue found throughout the submucosa of the small intestine commonly present as aggregate of lymphoid follicles known as Peyer's patches. ${ }^{[9]}$ These Peyer's patches increase in quantity in response to stimuli, such as viral infection. Lymphoid response to a variety of stimuli is most active during childhood. Adenoviruses and enteroviruses have been documented as example of such stimuli. Similar findings were seen in a study by Lena A Kombo et al.[10] The most common aetiology of intussusceptions in children is reported to be idiopathic in more than $90 \%$ of cases. In the present study, idiopathic intussusceptions was recorded in about $87.8 \%$ of cases in Sanjay Mehendale et al,[2] whereas in our study it was $31.9 \%$. Ileocecal site followed by ileoileal intussusception was earlier reported by another study from south India.[11] In our study, ileocecal intussusceptions was $82 \%$.

Appendix is a part of the intussusception of the commonest ileocolic type, but appendix as lead point for intussusceptions is rare. Joshi SB et al reported a series of three cases of intussusceptions in children, wherein a pathological appendix was the lead point compared to our study, in which there was $13.3 \%$. Appendix was the lead point for intussusception. [12-13]

Paediatric patients presenting with documented colocolic intussusceptions suggest a possibility of colonic polyp or other mass lesion in Mahmudloo et al.[14] In our study Juvenile colonic polyp has been reported to cause colocolic intussusceptions in $1.6 \%$ of the cases.

Primary gastrointestinal lymphoma represents $1-4 \%$ of all gastrointestinal malignancies with Burkitt's lymphoma accounting for $0.3-1.3 \%$ of all non-Hodgkin's lymphomas. BL accounts for only $1 \%-30 \%$ of all paediatric NHL representing a significant burden of disease in this age group. Most of the cases in children affect the distal ileum/ ileocecal region.[15] Similar findings have been reported by Krish Kulendran et al[16] that shows similar findings in our study too. The intestine is the most common site of primary extranodal lymphoma,[17] the usual clinical presentation is abdominal pain and a palpable right lower quadrant mass.[18] Less advanced cases may present with intussusceptions or intestinal obstructions. The histological findings showed the mucosa and submucosa are filled with sheets of uniform lymphoblastic cells.[19-22]

\section{CONCLUSION}

It is important to know the aetiology of Intussusceptions in paediatric age from benign to malignant lesions. Accurate diagnosis is essential, as treatment varies depending on aetiology which in turn varies from benign to malignant lesions.

\section{REFERENCES}

[1] John M, Siji CR. A clinical study of children with intussusception. Int J Contemp Pediatr 2016;3(3):10838.

[2] Mehendale S, Kumar CP, Venkatasubramaniam S, et al. Intussusception in children aged less than five years. The Indian Journal of Pediatrics 2016;83(10):1087-92. 
[3] Mathur S, Verseman S, Estrada R, et al. Bleeding from a Meckel's diverticulum after the use of ibuprofen. Am J Gastroenterol 1992;87(10):1467-70.

[4] Devanaboyna G, Singh-Ranger D, Shami S. Meckel's diverticulum causing mechanical small bowel obstruction. Canadian J Sur 2008;51(2):156.

[5] Maieron R, Stimac D, Avellini C, et al. Acute gastrointestinal bleeding due to Meckel's diverticulum heterotopic gastric mucosa. Ital J Gastroenterol 1996;28(4):225-8.

[6] Chan KW. Perforation of Meckel's diverticulum caused by a chicken bone: a case report. J Med Case Rep 2009;3:48.

[7] Al Jabri KA, El Sherbini A. Small bowel obstruction due to Meckel's diverticulum: a case report. Oman Medical J 2012;27(1):e029.

[8] Singhal BM, Kaval S, Sagar S, et al. Ileoileal intussusception due to Meckel's diverticulum: an uncommon aetiology. OA Surgery 2013;1(1):2.

[9] Danis RK. Lymphoid hyperplasia of the ileum - always a benign disease? Am J Dis Child 1974;127(5):656-62.

[10] Kombo LA, Gerber MA, Pickering LK, et al. Intussusception, Infection and immunization: summary of a workshop on rotavirus. Pediatrics 2001;108(2):E37.

[11] Bhowmick K, Kang G, Bose A, et al. Retrospective surveillance for intussusception in children aged less than five years in a south Indian tertiary-care hospital. J Health Popul Nutr 2009;27(5):660-5.

[12] Joshi SB, Kinhal V, Kola SK, et al. Intussusception in children with a pathological appendix acting as a "Lead Point" - a series of 3 cases. J Clin Diagn Res 2015;9(7):PD03-4.

[13] Abrahams RB, Franco A, Lewis KN. Pediatric colocolic intussusception with pathological lead point: a case report. Journal of Medical Cases 2012;3(1):84-8.
[14] Mahmudloo R, Gheibi S, Vahed SN. Colocolic intussusception without lead point: a case report and literature review. Iran J Pediatr 2008;18(4):373-6.

[15] Cogliatti SB, Novak U, Henz S, et al. Diagnosis of Burkitt's lymphoma in due time: a practical approach. Diagnostic Pathology 2007;2(Suppl 1):S6.

[16] Kulendran K, Choy KT, Keogh C, et al. An exceptional case of Ileocolic intussusception secondary to Burkitt's lymphoma: What variations are there in the presentation and management of those patients who approach adolescence? Article ID 6251321, Case Reports in Surgery 2018;2018: p. 5.

[17] Zinzani PL, Magagnoli M, Pagliani G, et al. Primary intestinal lymphoma: clinical and therapeutic features of 32 patients. Haematologica 1997;82(3):305-8.

[18] Ghimire P, Wu GY, Zhu L. Primary gastrointestinal lymphoma. World J Gastroenterol 2011;17(6):697707.

[19] Hoxha FT, Hashani SI, Krasniqi AS, et al. Intussusceptions as acute abdomen caused by Burkitt lymphoma: a case report. Cases Journal 2009;2(1):9322.

[20] Bernardi D, Asti E, Bonavina L. Adult ileocolic intussusception caused by Burkitt lymphoma. BMJ Case Reports 2016.

[21] Wang SM, Huang FC, Wu CH, et al. Ileocecal Burkitt's lymphoma presenting as ileocolic intussusception with appendiceal invagination and acute appendicitis. Journal of the Formosan Medical Association 2010;109(6):476-9.

[22] Bethel CA, Bhattacharyya N, Hutchinson C, et al. Alimentary tract malignancies in children. Journal of Pediatric Surgery 1997;32(7):1004-9. 